Jpn. J. Genet. (1986) 61, pp. 559-568

\title{
Gene dosage effects of amylose content in rice endosperm
}

\author{
By Ish Kumar and G. S. KHUSH \\ International Rice Research Institute, \\ Los Banos, Laguna, Philippines \\ (Received July 21, 1986)
}

\begin{abstract}
Seven indica rice varieties with different amylose contents were crossed in all possible combinations including reciprocals. Single grains of parents and $\mathrm{F}_{1}$ 's were analyzed to determine the dosage effects of genes responsible for different amylose contents. Different genes for amylose content showed differential effects on endosperm appearance and amylose production in the $\mathrm{F}_{1}$. A single dose of very low or low amylose gene was not capable of producing amylose to the level of their non-waxy parent in waxy/non-waxy crosses. The effect of one dose of gene for intermediate or high amylose was highly conspicious with relatively less dosage effect. Dosage effects were observed in both waxy/non-waxy and among non-waxy crosses. In general, amylose content increased with increase in gene dosage though not in a linear fashion. Cases where amylose content decreased with increase in dosage for higher amylose have also been observed. The importance of such results in understanding the inheritance pattern of this trait has been discussed.
\end{abstract}

\section{INTRODUCTION}

Amylose content in rice is one of the chief components that determine cooking quality. Rices with different amylose contents are preferred in different countries. Wide variations in amylose content occur and varieties with different amylose contents varying from $0-2 \%$ amylose (waxy), very low (3 $-9 \%)$, low (10-19\%), intermediate $(20-25 \%)$ and high $(>25 \%)$ have been selected. However, no information is available on the amylose content of $F_{1}$ seeds obtained from crosses beteen parents with varying amylose content. The present study was undertaken to study the dosage effect of genes controlling various levels of amylose content. Such information is necessary for predicting the cooking quality characteristics of $F_{1}$ hybrid varieties and in analyzing the inheritance pattern of different amylose levels in the segreating populations.

\section{MATERIALS AND METHODS}

Seven indica rice varieties representing all amylose classes-IR29 (waxy); IR37307-8 (very low); IR3351-38 and IR24 (low); BPI 121-407 and IR2463234 (intermediate); and IR8 (high)-were crossed in all possible combinations during the 1985 dry season (DS) at the International Rice Research Institute 
(IRRI), at Los Banos, Philippines. IR29, being a waxy variety, had opaque endosperm while line IR37307-8's endosperm had a dull appearance. All other varieties had translucent endosperms. The seeds of all the parents and their $F_{1}$ 's were dehulled and milled in a Wig-L-Bug. Phenotypic scoring on endosperm appearance of parents and $F_{1}$ seeds were done in all the crosses. Ten seeds of each of the parents and their $\mathrm{F}_{1}$ 's (crossed seed) were analyzed for amylose content in two replications. The analysis was done by Technicon autoanalyzer following Juliano's procedure (1971). The data obtained were analyzed in randomized block design to find out the difference between the parents and their hybrids. Reciprocal crosses were used to evaluate dosage effect. To find out the change in amylose content by dosage, the amylose content in the higher parent of the cross was taken as 100 . The amylose content in the low amylose parent of the cross and both its $F_{1}$ 's was calculated as a percentage of the higher amylose parent. The percent change by each dose was then calculated by subtracting the percent amylose of the lower dose from the next higher dose. The SE'd was used to compare any significant difference due to gene dosage. The change of amylose content due to each dose (as \% of higher amylose parent in each cross) was marked for this significant change.

\section{RESULTS}

The mean values for amylose content of parents and $F_{1}$ 's are presented in Table 1. Analysis of variance shows significant difierences between the parents and their hybrids. Changes in amylose content (expressed as percent of higher amylose parent of the cross) due to difierent gene dosages in difierent crosses are given in Table 2.

Crosses with waxy parent:

It is evident from Tables 1 and 2 that crosses of difierent parents with IR29 as the female parent produced a differential effect on the amylose content in the endosperm of $F_{1}$ seeds. One dose of very low amylose gene was unable to increase the amylose content significantly above that of the waxy parent. The second dose increased the amylose content by a margin of $21.32 \%$ over that of the first dose or by a margin of $41.56 \%$ over the waxy female parent, IR29. The third dose was found to be most effective in significantly increasing the amylose content by a margin of $58.30 \%$ over the second dose. In the cross with IR3351-38, one dose of low amylose gene significantly increased amylose content by a margin of $45.12 \%$ over that of the waxy parent. The second dose did not increase the amylose content significantly over the first dose. The third dose showed an increase of $51.63 \%$ over the second dose. In the cross with the second low amylose parent (IR24), all three doses showed significant increase of $36.93,43.88$, and $19.12 \%$ over 0,1 and 2 doses, 
Table 1. Mean values for amylose content and endosperm appearance in parents and hybrids of rice.

\begin{tabular}{|c|c|c|c|c|}
\hline \multirow{2}{*}{ Crosses $\left(\mathrm{P}_{1} / \mathrm{P}_{2}\right)$} & \multicolumn{4}{|c|}{ Amylose (Percent) } \\
\hline & $\mathrm{P}_{1}$ & $\begin{array}{c}\mathrm{F} 1 \\
\left(\mathrm{P}_{1} / \mathrm{P}_{2}\right)\end{array}$ & $\begin{array}{c}\mathrm{Fl} \\
\left(\mathrm{P}_{2} / \mathrm{P}_{1}\right)\end{array}$ & P2 \\
\hline IR29/IR37307-8 & $0.01(0)$ & $1.51(0)$ & $3.09(\mathrm{D})$ & 7.41 (D) \\
\hline IR29/IR3351-38 & $0.01(0)$ & $5.70(\mathrm{D})$ & $6.10(\mathrm{D})$ & $12.61(\mathrm{~T})$ \\
\hline IR29/IR24 & $0.01(0)$ & $5.59(\mathrm{D})$ & $12.22(\mathrm{~T})$ & $15.11(\mathrm{~T})$ \\
\hline IR29/IR24632-34 & $0.01(0)$ & $21.05(\mathrm{~T})$ & $22.43(\mathrm{~T})$ & $21.74(\mathrm{~T})$ \\
\hline IR29/BPI 121-407 & $0.01(0)$ & $22.92(\mathrm{~T})$ & $22.40(\mathrm{~T})$ & $24.89(\mathrm{~T})$ \\
\hline IR29/IR8 & $0.01(0)$ & $23.88(\mathrm{~T})$ & $27.52(\mathrm{~T})$ & $27.26(\mathrm{~T})$ \\
\hline IR37307-8/IR3351-38 & 7.41 (D) & $11.12(\mathrm{D})$ & $7.88(\mathrm{D})$ & $12.61(\mathrm{~T})$ \\
\hline IR37307-8/IR24 & 7.41 (D) & $6.86(\mathrm{D})$ & $12.88(\mathrm{~T})$ & $15.11(\mathrm{~T})$ \\
\hline IR37307-8/IR24632-34 & 7.41 (D) & $17.45(\mathrm{D})$ & $15.91(\mathrm{~T})$ & $21.74(\mathrm{~T})$ \\
\hline IR37307-8/BPI 121-407 & 7.41 (D) & $13.94(\mathrm{D})$ & $18.65(\mathrm{~T})$ & $24.89(\mathrm{~T})$ \\
\hline IR37307-8/IR8 & 7.41 (D) & $23.47(\mathrm{~T})$ & $26.88(\mathrm{~T})$ & $27.26(\mathrm{~T})$ \\
\hline IR3351-38/IR24 & $12.61(\mathrm{~T})$ & $9.45(\mathrm{~T})$ & $14.12(\mathrm{~T})$ & $15.11(\mathrm{~T})$ \\
\hline IR3351-38/IR24632-34 & $12.61(\mathrm{~T})$ & $23.70(\mathrm{~T})$ & $24.61(\mathrm{~T})$ & $21.74(\mathrm{~T})$ \\
\hline IR3351-38/BPI 121-407 & $12.61(\mathrm{~T})$ & $23.28(\mathrm{~T})$ & $23.92(\mathrm{~T})$ & $24.89(\mathrm{~T})$ \\
\hline IR3351-38/IR8 & $12.61(\mathrm{~T})$ & $26.22(\mathrm{~T})$ & $24.89(\mathrm{~T})$ & $27.26(\mathrm{~T})$ \\
\hline IR24/IR24632-34 & $15.11(\mathrm{~T})$ & $26.32(\mathrm{~T})$ & $21.78(\mathrm{~T})$ & $21.74(\mathrm{~T})$ \\
\hline IR24/BPI 121-407 & $15.11(\mathrm{~T})$ & $27.21(\mathrm{~T})$ & $24.47(\mathrm{~T})$ & $24.89(\mathrm{~T})$ \\
\hline IR24/IR8 & $15.11(\mathrm{~T})$ & $27.96(\mathrm{~T})$ & $25.24(\mathrm{~T})$ & $27.26(\mathrm{~T})$ \\
\hline IR24632-34/BPI 121-407 & $21.74(\mathrm{~T})$ & $22.85(\mathrm{~T})$ & $23.60(\mathrm{~T})$ & $24.89(\mathrm{~T})$ \\
\hline IR24632-34/IR8 & $21.74(\mathrm{~T})$ & $25.61(\mathrm{~T})$ & $27.05(\mathrm{~T})$ & $27.26(\mathrm{~T})$ \\
\hline BPI $121-407 / I R 8$ & $24.89(\mathrm{~T})$ & $26.43(\mathrm{~T})$ & $29.27(\mathrm{~T})$ & $27.26(\mathrm{~T})$ \\
\hline
\end{tabular}

Note: Figure in parenthesis indicates endosperm appearance: $\mathrm{O}=$ opaque $\mathrm{D}=$ dull $\mathrm{T}=$ translucent

respectively. In crosses involving intermediate or high amylose parents, the first doses increased the amylose content to a much larger extent $(87.56 \%$ to $96.78 \%$ ) as compared to the second and third doses whose contribution was marginal (Table 2).

The endosperm appearance of $\mathrm{F}_{1}$ seeds of waxy/non-waxy crosses or their reciprocals varied according to the amylose content in the non-waxy parent and the dosage of gene for waxy endosperm. In cross of waxy and very lowamylose content (dull endosperm) parents, the $F_{1}$ seeds had opaque endosperm (Fig. 1). In crosses of waxy variety with low-amylose content varieties as pollen parent, the $F_{1}$ had a dull endosperm appearance which could easily be distinguished from either of the parents (Fig. 2). On the other hand, the endosperm of $F_{1}$ seeds was translucent when lines with intermediate or high amylose content were used as pollen parents (Table 3, Fig. 3 and 4). 
Table 2. Change in amylose content of rice grain due to each dose.

\begin{tabular}{|c|c|c|c|c|}
\hline \multirow{3}{*}{ Crosses } & \multirow{2}{*}{\multicolumn{4}{|c|}{$\begin{array}{l}\text { Change in amylose by gene dosage } \\
\text { (as \% of higher amylose parent) } \\
\text { Doses of higher amylose parent }\end{array}$}} \\
\hline & & & & \\
\hline & dose & $\begin{array}{l}\text { First } \\
\text { dose }\end{array}$ & $\begin{array}{l}\text { Second } \\
\text { dose }\end{array}$ & $\begin{array}{l}\text { Third } \\
\text { dose }\end{array}$ \\
\hline IR29/IR37307-8 & 0.13 & 20.24 & 21.32 & $58.30^{* *}$ \\
\hline IR29/IR3351-38 & 0.08 & $45.12^{* *}$ & 3.17 & $51.63^{* *}$ \\
\hline IR29/IR24 & 0.07 & $36.93^{* *}$ & $43.88 * *$ & $19.12^{*}$ \\
\hline IR29/IR24632-34 & 0.04 & $96.78^{* *}$ & 6.34 & -3.17 \\
\hline IR29/BPI 121-407 & 0.04 & $92.04^{* *}$ & -2.09 & $10.00^{* *}$ \\
\hline IR29/IR8 & 0.04 & $87.56^{* *}$ & $13.35^{* *}$ & -0.95 \\
\hline IR37307-8/IR3351-38 & 58.76 & $29.42^{* *}$ & $-25.69 * *$ & $37.51^{* *}$ \\
\hline IR37307-8/IR24 & 49.04 & -3.64 & $39.84^{* *}$ & 14.76 \\
\hline IR37307-8/IR24632-34 & 34.08 & $46.18^{* *}$ & -7.08 & $26.82^{* *}$ \\
\hline IR37307-8/BPI 121-407 & 29.77 & $26.23^{* *}$ & $18.92 * *$ & $25.07^{* *}$ \\
\hline IR37307-8/IR8 & 27.18 & $58.91 * *$ & $12.51^{* *}$ & 1.39 \\
\hline IR3351-38/IR24 & 83.45 & $-20.91 * *$ & $30.91^{* *}$ & 6.55 \\
\hline IR3351-38/IR24632-34 & 58.00 & $51.01 * *$ & 4.19 & $-13.20^{*}$ \\
\hline IR3351-38/BPI 121-407 & 50.66 & $42.87 * *$ & 2.57 & 3.90 \\
\hline IR3351-38/IR8 & 46.26 & $49.93^{* *}$ & -4.88 & 8.69 \\
\hline IR24/IR24632-34 & 69.50 & $51.56^{* *}$ & $-20.88^{* *}$ & -0.19 \\
\hline IR24/BPI 121-407 & 60.70 & $48.61^{* *}$ & $-11.01^{*}$ & 1.69 \\
\hline IR24/IR8 & 55.43 & $47.14^{* *}$ & $-9.98^{*}$ & 7.41 \\
\hline IR24632-34/BPI 121-407 & 87.34 & 4.46 & 3.01 & 5.18 \\
\hline IR24632-34/IR8 & 79.75 & $14.20 * *$ & 5.28 & 0.77 \\
\hline BPI 121-407/IR8 & 91.30 & 5.65 & $10.42^{*}$ & -7.37 \\
\hline
\end{tabular}

Crosses with very-low amylose parent:

In crosses with low amylose parent except in the cross IR37307-8/IR24, the first dose significantly increased the amylose in $\mathrm{F}_{1}$ seeds by a margin of 26.23 to $58.91 \%$. The first dose of the low amylose parent IR3351-38 showed an amylose increase of $29.42 \%$ over that of the very low amylose parent, IR373078. The second dose, however, showed a significant decrease $(-25.69 \%)$. The third dose showed an increase of $37.51 \%$ over the second dose. In the cross IR37307-8/IR24, only the second dose significantly enhanced the amylose content by $39.84 \%$ over the first dose. In the cross IR37307-8/IR24632-34, only the first and third doses increased the amylose content. On the other hand, all the three doses in the cross IR37307-8/BPI 121-407 significantly enhanced the amylose content. In the cross IR37307-8/IR8, the first dose was most effective and increased the amylose by $58.91 \%$ over that of the very low 


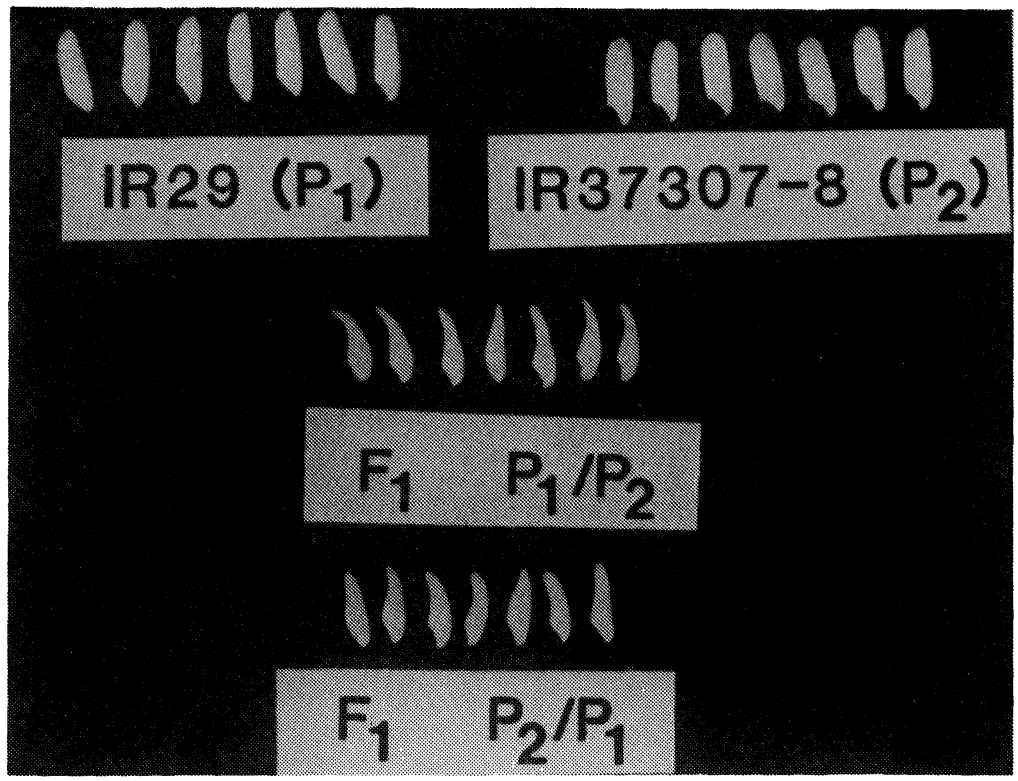

Fig. 1. $\mathrm{P}_{1}$-opaque; $\mathrm{P}_{2}$-dull; $\mathrm{P}_{1} / \mathrm{P}_{2}$-opaque; $\mathrm{P}_{2} / \mathrm{P}_{1}$-opaque

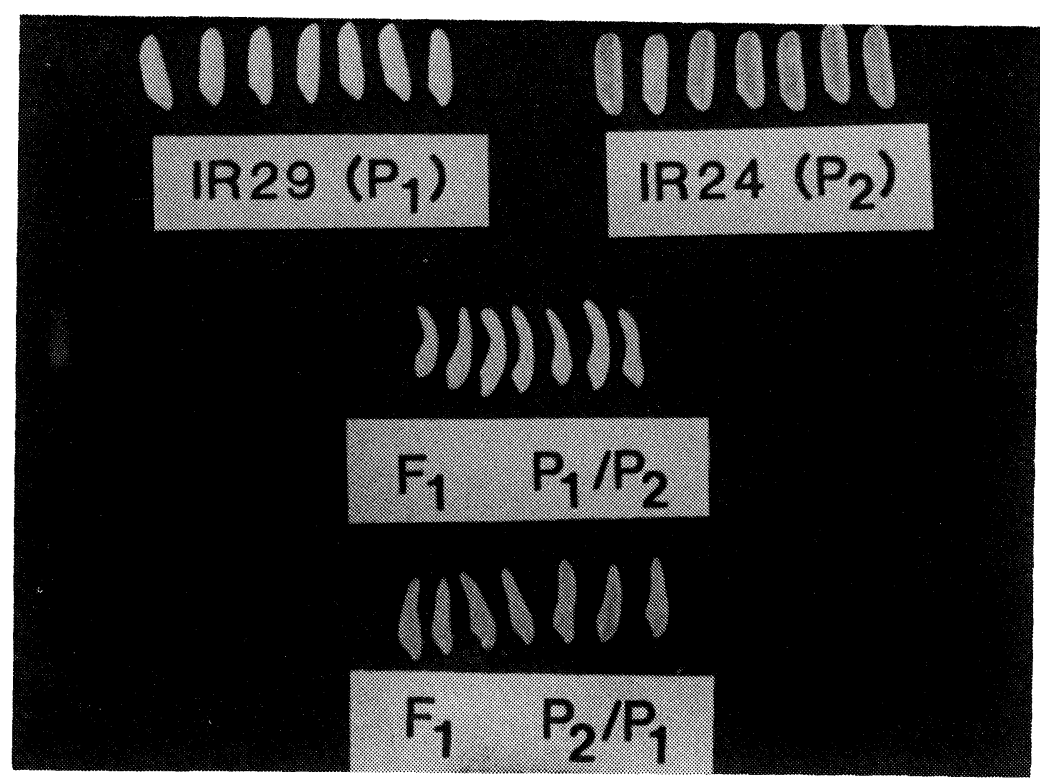

Fig. 2. $\mathrm{P}_{1}$-opaque; $\mathrm{P}_{2}$-translucent; $\mathrm{P}_{1} / \mathrm{P}_{2}$-hazy $; \mathrm{P}_{2} / \mathrm{P}_{1}$-translucent 


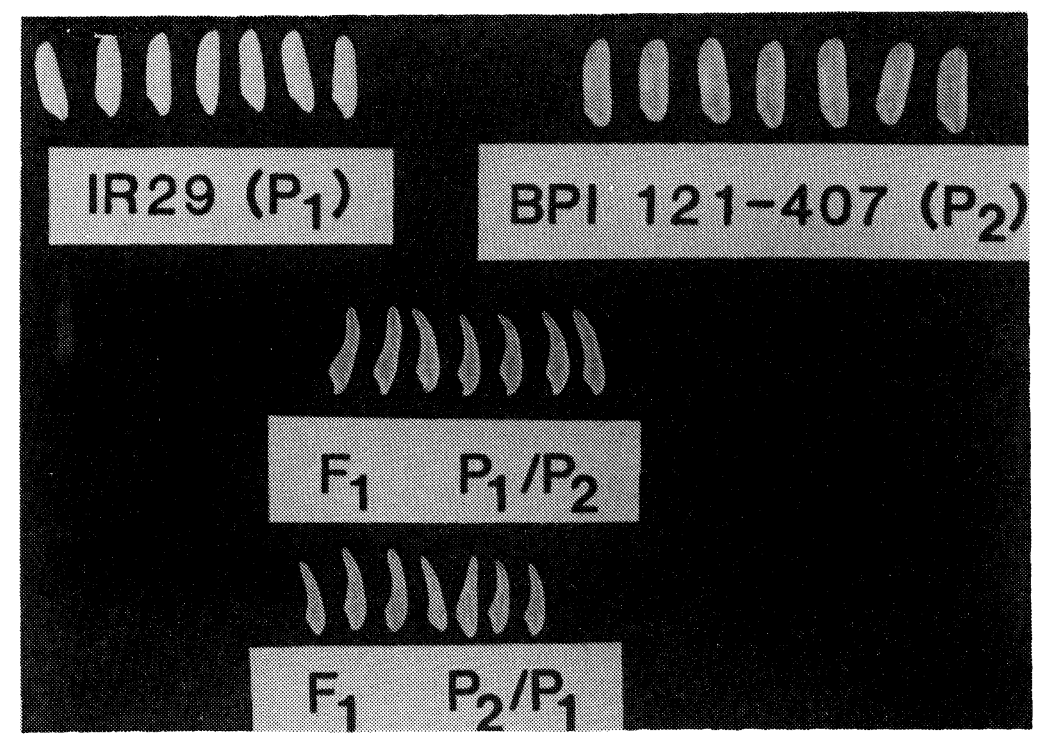

Fig. 3. $\mathrm{P}_{1}$-opaque; $\mathrm{P}_{2}$-translucent; $\mathrm{P}_{1} / \mathrm{P}_{2}$-translucent; $\mathrm{P}_{2} / \mathrm{P}_{1}$-translucent

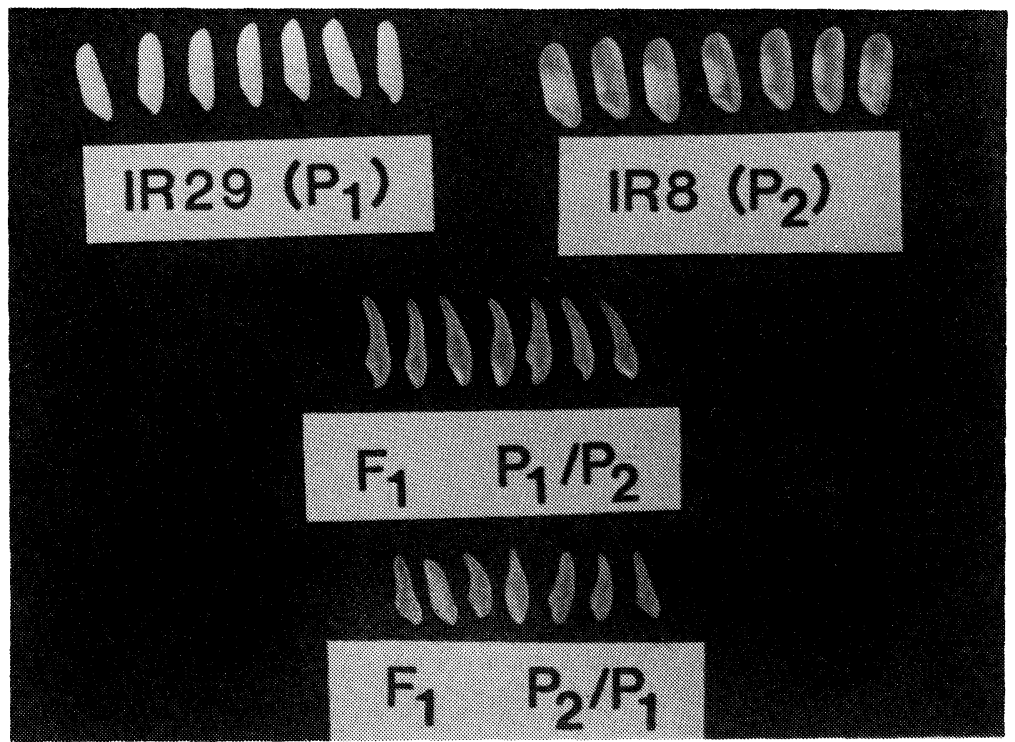

Fig. 4. $\mathrm{P}_{1}$-opaque; $\mathrm{P}_{2}$-translucent; $\mathrm{P}_{1} / \mathrm{P}_{2}$-translucent; $\mathrm{P}_{2} / \mathrm{P}_{1}$-translucent 


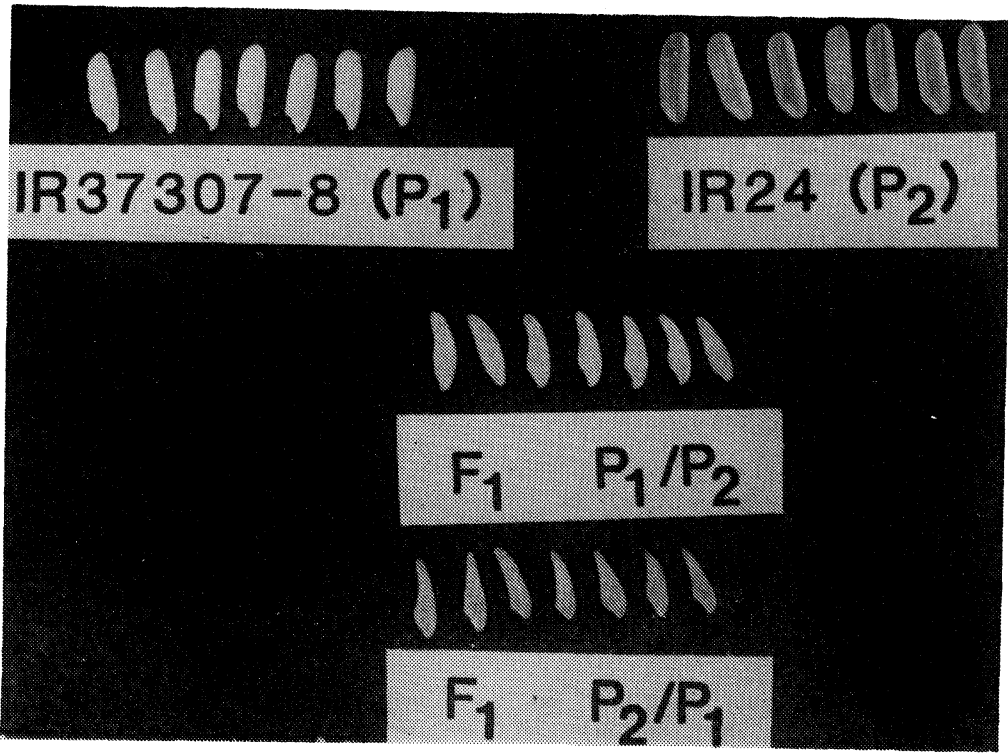

Fig. 5. $\mathrm{P}_{1}$-dull; $\mathrm{P}_{2}$-translucent; $\mathrm{P}_{1} / \mathrm{P}_{2}$-dull; $\mathrm{P}_{2} / \mathrm{P}_{1}$-translucent

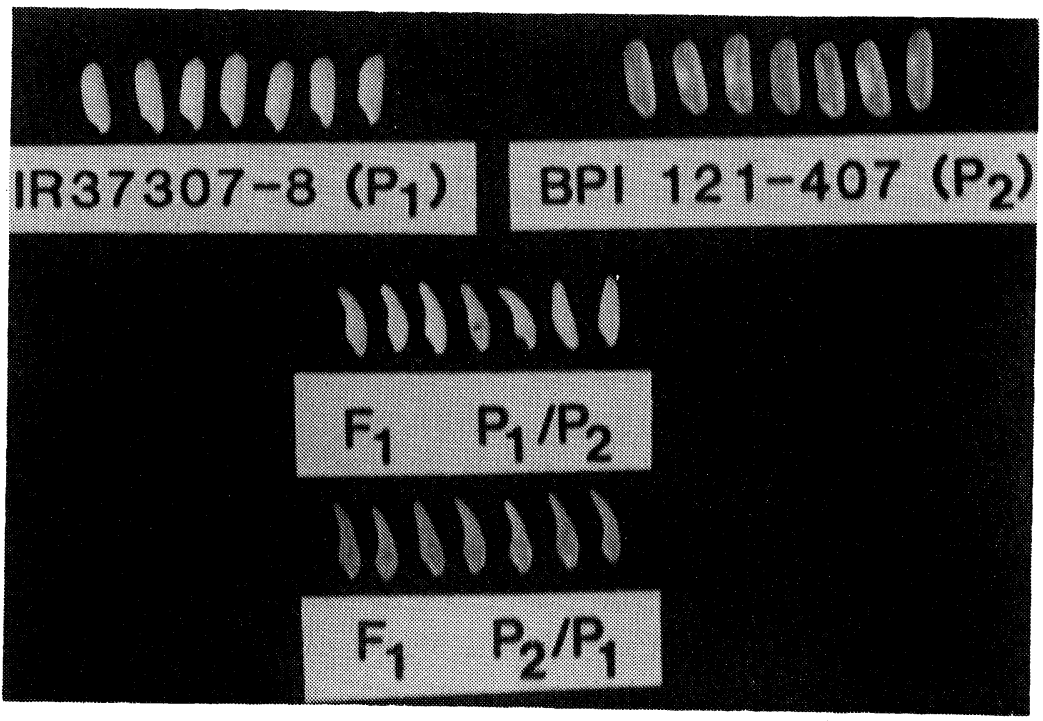

Fig. 6. $\mathrm{P}_{1}$-dull; $\mathrm{P}_{2}$-translucent; $\mathrm{P}_{1} / \mathrm{P}_{2^{-}}$-dull; $\mathrm{P}_{2} / \mathrm{P}_{1}$-translucent 


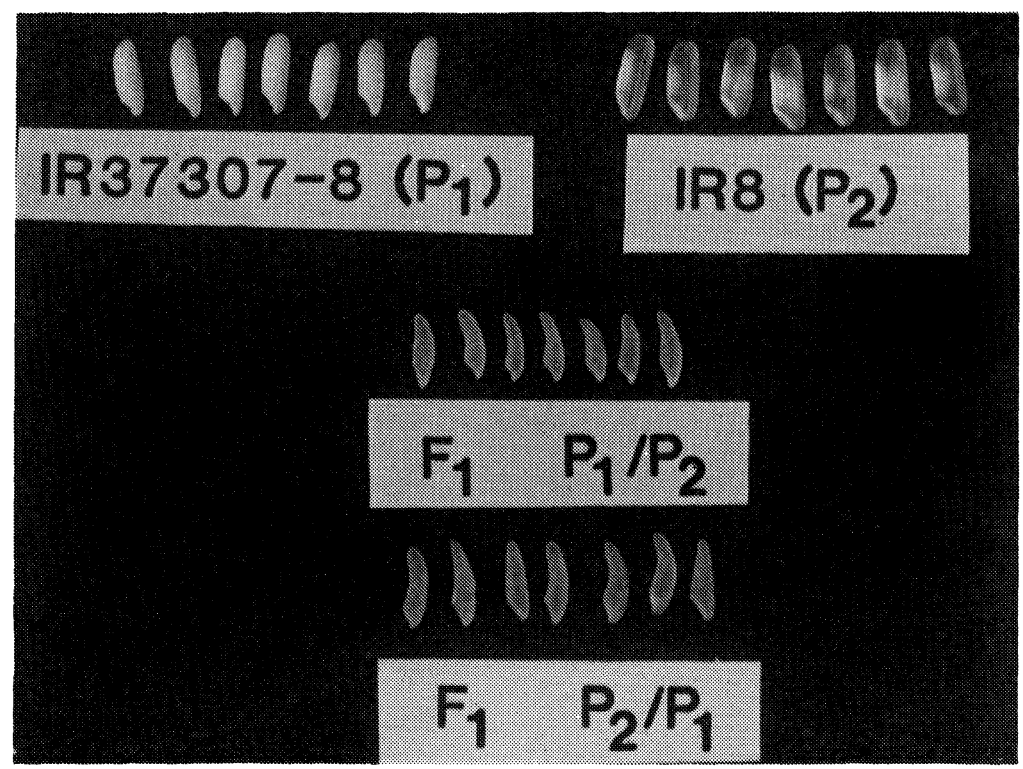

Fig. 7. $\mathrm{P}_{1}$-dull; $\mathrm{P}_{2}$-translucent; $\mathrm{P}_{1} / \mathrm{P}_{2}$-translucent; $\mathrm{P}_{2} / \mathrm{P}_{1}$-translucent

amylose parent. The second dose further increased the amylose level by $12.51 \%$ over the first dose.

Endosperm appearance of $F_{1}$ seeds in crosses of very low-amylose content line IR37307-8 (dull endosperm) with other non-waxy varieties of varying amylose content was slightly different. When varieties with low and intermediate amylose content were used as pollen parent, the endosperm appearance was dull. With a high amylose content variety as pollen parent, it was translucent (Table 3, Fig. 5-7).

Crosses with low amylose parent:

One dose of the intermediate amylose gene in the cross IR3351-38/IR2463234 increased the amylose content slightly beyond the average level of the intermediate amylose parent IR24632-34. The second dose did not show any significant difference from the first dose. The third dose decreased the amylose content slightly. The first dose in crosses IR3351-38/BPI 121-407 and IR3351-38/IR8 caused a major significant increase over that of the low amylose parent. The second and third doses caused only marginal differences. In crosses with the second low amylose variety IR24, one dose of gene for intermediate or high amylose content increased the $\mathrm{F}_{1}$ amylose content by a margin of 47.14 to $51.56 \%$. However, a decreasing trend in amylose content was observed with an increase in dosage (Tables 1 and 2).

The $\mathrm{F}_{1}$ endosperm of all the above crosses was translucent. 


\section{Crosses with intermediate amylose parent:}

In the cross IR24632-34/IR8, a significant increase in amylose content was seen with the first dose. The second and third doses only marginally increased the amylose level. In the cross BPI 121-407/IR8, only the second dose significantly enhanced the amylose content over the first dose. No significant increase in amylose level was observed in $\mathrm{F}_{1}$ seeds of crosses between the two intermediate amylose parents, IR24632-34 and BPI 121-407. The $\mathrm{F}_{1}$ endosperm was translucent in all the crosses.

\section{DISCUSSION}

In the study of the genetics of quality traits like amylose content, we are concerned with the edible part of the seed, i.e., the endosperm. The endosperm is a triploid tissue having one dose of paternal alleles and two doses of the maternal. In view of this, it is possible to study the effect of waxy or non-waxy (having different amylose content) gene dosage, and endosperm appearance. The starch produced in the non-waxy endosperm is composed of 3 to $34 \%$ amylose, whereas waxy rices contain primarily amylopectin and are either devoid of any amylose or only have a trace of this fraction of starch.

In this study, it was observed that in waxy/non-waxy crosses, one dose of gene for very low- or low-amylose content is not sufficient to alter the appearance of $F_{1}$ endosperm or enhance the amylose content of the $F_{1}$ seeds to the level of the pollen parent. However, when the pollen parent had either intermediate or high amylose content, one dose of the higher amylose gene was sufficient to produce amylose content and alter endosperm appearance similar to that of the pollen parent. In case of crosses involving waxy and very low or low amylose content parents even 2 doses of gene for low or very low amylose content were not sufficient to enhance amylose content though this level was higher than those with one dose. Dosage effects were also observed by Okuno (1978) in cross between waxy and low amylose parent, IRRI (1976), Heu and Park (1976 a,b), Okuno and Yano (1984), and Sano (1984) in crosses between waxy and non-waxy parents.

In crosses of very-low-amylose parent with other non-waxy parents (such as those having low, intermediate or high amylose content), the dosage effects were significant. This indicates that for genes controlling endosperm characters, a specific gene dosage is necessary to express such properties. This is evident because in some cases, only single, in others two, and in still others, three doses of the gene were necessary for a full expression of the amylose content or appearance of the endosperm. In crosses involving a lowamylose content parent (IR3351-38), and intermediate or high amylose content parents, some dosage effects have been observed. However, in crosses of the other low amylose content parent (IR24) with intermediate or high amylose parents, 
negative effects resulted: the amylose content decreased with an increase of dosage. Some dosage effects in crosses involving intermediate and high amylose parents have been noted. Sano (1984) also showed different gene dosage effects of parents having different amylose contents. He attributed this to different levels of gene product by different genes. The one producing a higher level of Wx protein had higher amylose than the one producing lower level of Wx protein. From the present study, a single dose of gene for intermediate or high amylose content appears potent enough to produce the same amylose level as that of the pollen parent. Such genes may be producing a higher level of gene product which is sufficient to produce higher amylose or suppress branching activity to check amylopectin synthesis. On the other hand, with one or two doses of gene for very low or low amylose content, the level of Wx protein producing higher amylose may not be high. This should be confirmed by studying the level of $\mathrm{Wx}$ protein in seeds with different amylose contents.

The information on dosage effect in waxy/non-waxy and among non-waxy crosses would be helpful in understanding the segregation pattern for amylose content in different generations. Occurrence of different classes on the basis of dosage effect would be helpful in explaining the mode of inheritance of this important trait.

\section{REFERENCES}

Hev, M. H. and PARK, S. Z. (1976) (a) Dosage effect of waxy allele on the amylose content of rice grain I. Amylose content of hybrid seeds obtained from isogeniclines for glutinuous and base colour. Korean J. Breed. 8, 48-54.

HeU, M. H. and PARK, S. Z. (1976) (b) Dosage effect of waxy gene on the amylose content of rice grain II. Amylose content of hybrid seeds obtained from male sterile stocks. Seoul Natl. Univ. Coll. Agric. Bull. 1, 39-46.

International Rice Research Institute. (1976) Annual report for 1975. Los Banos, Philippines.

Juliano, B. O. (1971) A simplified assay for milled rice amylose. Cereal Scie. Today 16, 334$338,340,360$.

OKuno, K. (1978) Gene dosage effect of waxy alleles on amylose content in endosperm starch of rice. Jap. J. Genet. 53, 219-222.

OKuno, K. and YaNo, M. (1984) New endosperm mutants modifying starch characteristics of rice Oryza Sativa L. JARQ 18, 73-84.

SANo, Y. (1984) Differential regulation of waxy gene expression in rice endosperm. Theor. Appl. Genet. 68, 467-473. 